\title{
Lung tumor promotion by chromium-containing welding particulate matter in a mouse model
}

\author{
Patti C Zeidler-Erdely*, Terence G Meighan, Aaron Erdely, Lori A Battelli, Michael L Kashon, Michael Keane \\ and James M Antonini
}

\begin{abstract}
Background: Epidemiology suggests that occupational exposure to welding particulate matter (PM) may increase lung cancer risk. However, animal studies are lacking to conclusively link welding with an increased risk. PM derived from stainless steel (SS) welding contains carcinogenic metals such as hexavalent chromium and nickel. We hypothesized that welding PM may act as a tumor promoter and increase lung tumor multiplicity in vivo. Therefore, the capacity of chromium-containing gas metal arc (GMA)-SS welding PM to promote lung tumors was evaluated using a two-stage (initiation-promotion) model in lung tumor susceptible A/J mice.
\end{abstract}

Methods: Male mice ( $n=28$-30/group) were treated either with the initiator 3-methylcholanthrene (MCA;10 $\mu \mathrm{g} / \mathrm{g} ; \mathrm{IP})$ or vehicle (corn oil) followed by 5 weekly pharyngeal aspirations of GMA-SS (340 or $680 \mu \mathrm{g} / \mathrm{exposure)} \mathrm{or} \mathrm{PBS.} \mathrm{Lung}$ tumors were enumerated at 30 weeks post-initiation.

Results: MCA initiation followed by GMA-SS welding PM exposure promoted tumor multiplicity in both the low (12.1 \pm 1.5 tumors/mouse) and high (14.0 \pm 1.8 tumors/mouse) exposure groups significantly above MCA/sham (4.77 \pm 0.7 tumors/mouse; $p=0.0001)$. Multiplicity was also highly significant $(p<0.004)$ across all individual lung regions of GMA-SS-exposed mice. No exposure effects were found in the corn oil groups at 30 weeks. Histopathology confirmed the gross findings and revealed increased inflammation and a greater number of malignant lesions in the MCA/welding PM-exposed groups.

Conclusions: GMA-SS welding PM acts as a lung tumor promoter in vivo. Thus, this study provides animal evidence to support the epidemiological data that show welders have an increased lung cancer risk.

Keywords: AJJ mouse, Cancer, Chromium, Nickel, Welding

\section{Introduction}

Welding, a process used to join metals, is common in the manufacturing, construction, and other industrial sectors in the U.S. and worldwide. Daily, millions of workers are exposed to welding fume, a complex aerosol mixture of gases and metal-rich particulate matter (PM). Because of the presence of known human carcinogens, such as hexavalent chromium $(\mathrm{Cr}(\mathrm{VI}))$ and nickel $(\mathrm{Ni})$, the potential carcinogenicity of welding fume is a critical concern in occupational toxicology. In fact, the International Agency for Research on Cancer (IARC) advisory group on the Monograph priorities for 2010-2014 listed welding fume as a high priority agent for further evaluation of carcinogenic

\footnotetext{
* Correspondence: paz9@cdc.gov

Health Effects Laboratory Division, National Institute for Occupational Safety and Health, 1095 Willowdale Road MS L2015, Morgantown, WV 26505, USA
}

risk to humans [1]. Currently, the IARC classifies welding fumes as a group 2B carcinogen (possibly carcinogenic to humans); however, this categorization was based on limited epidemiology and inadequate animal data [2-4].

Occupational exposure to welding fume is unique and presents numerous physical (e.g. heat and UV radiation) and chemical hazards to the worker. Mixtures of metal compounds of iron $(\mathrm{Fe}), \mathrm{Cr}(\mathrm{VI})$, manganese $(\mathrm{Mn}), \mathrm{Ni}$, and gases (e.g., ozone, carbon monoxide, nitrogen oxides) all may be present in the fume [5,6]. In addition, the fume is classified as an incidental nanoparticle as significant numbers of ultrafine $(<0.1 \mu \mathrm{m})$ particles are formed during the welding process [7]. As such, both respiratory and nonrespiratory adverse health effects are well-documented in workers and can include bronchitis, immunosuppression, 
pneumonia, metal fume fever, siderosis, and neurological effects $[5,8]$.

Fume generated during gas metal arc (GMA)-stainless steel (SS) welding is largely water-insoluble and closely resembles the metal composition of the consumable electrode wire used [5]. $\mathrm{Cr}(\mathrm{VI})$ and $\mathrm{Ni}$ are present in significant amounts in this fume and are necessary for corrosion protection of the weld [9]. Previous experimental evidence showed that welding PM, from SS welding wire in particular, caused epithelial injury as well as atypical and hyperplastic cellular changes in the lungs of mice. Interestingly, a mild chronic lung inflammation was accompanied by an increased persistence of these fumes in situ [10,11]. In addition, evidence for a weak (borderline significant) carcinogenic effect in lung tumor susceptible mice was found for PM from GMA-SS welding, one of the most prevalent workplace processes [11]. Predicated on these findings and suggestions by the IARC, this current study is a continuation of previous investigations by our laboratory to evaluate the carcinogenic potential of welding fume. Here, we focus on carcinogenic metal-containing SS welding PM as a tumor promoter using a two-stage (initiation-promotion) mouse lung tumor bioassay.

\section{Results}

\section{Welding fume $\mathrm{PM} \mathrm{Cr}(\mathrm{VI})$ and total metal analysis}

GMA-SS welding PM contained the following metals (weight \%): $\mathrm{Cr}$ (20.2), copper [Cu] (0.2), iron [Fe] (57), Mn (13.8) and $\mathrm{Ni}(8.8)$ with trace amounts of silicon, aluminum, and vanadium. $\mathrm{Cr}(\mathrm{VI})$ levels in the fume were $2929 \mathrm{ppm}$ $(\mu \mathrm{g} / \mathrm{g})(\mathrm{n}=3, \mathrm{SD}=120)$.

\section{Morbidity and mortality}

A timeline of the experimental protocol for the two-stage (initiation-promotion) carcinogenesis model is shown in Figure 1 and described in detail in the methods section. Body weights were recorded at 2 week intervals throughout the study and no effect of exposure was found. Body weight changes from week 0 to 30 were (mean \pm standard error [SE] $6.83 \pm 0.27,7.19 \pm 0.37$, and $6.41 \pm 0.37$ for the corn oil/sham, GMA-SS low and high groups, respectively. For the MCA/sham, GMA-SS low and high groups body weight changes were $7.30 \pm 0.36,7.36 \pm 0.39$ and $7.23 \pm$ 0.31 , respectively. Morbidity and mortality throughout the study was low and no abnormalities, such as other tumor types besides lung, were found at the terminal sacrifice at 30 weeks. In total, 13 mice died during the course of the study ( $\sim 93 \%$ survival rate) and were not included in the final analysis of the data. Of the $>880$ pharyngeal aspirations performed for the study, 4 mice died from effects likely related to anesthesia during the exposures. Nine mice died with typical morbidities including head tilt, scrotal or mesenteric abscesses, kidney masses, enlarged hearts or from unknown causes. This indicated that the experimental protocol was well tolerated.

\section{Gross tumor multiplicity and incidence}

In the presence of MCA, GMA-SS welding PM was a highly significant promoter of lung tumor number in the $\mathrm{A} / \mathrm{J}$ mouse 30 weeks after initiation. Figure 2 shows the grossly observed tumor multiplicity (average tumor number/mouse lung \pm SE) (left panel) and the total tumor numbers (right panel) for all groups. Tumor multiplicity in the low and high dose group was $12.1 \pm 1.5(p=0.0001)$ and $14.0 \pm 1.8 \quad(p=0.0001)$, respectively, compared to MCA/sham $4.77 \pm 0.7$ Multiplicity was also highly significant across all five individual lung regions of GMA-SS-exposed mice $(p<0.004)$ (Table 1$)$. In the corn oil groups, tumor multiplicity was $0.21 \pm 0.09,0.42 \pm 0.11,0.21 \pm 0.08$ in the sham, GMA-SS low and high groups, respectively, and was not significant across exposure groups. No significant difference in multiplicity was found between the low and high dose GMA-SS groups initiated with corn oil or MCA. Average tumor incidence (\% of tumor-bearing mice) was $25.8 \pm 6.4 \%$ and was not significantly different across exposure groups treated with corn oil. As expected, incidence was $>93 \%$ in all MCA-initiated groups which verified successful experimental administration as well its carcinogenic effectiveness in A/J mice.

Gross lung morphology from a welding PM-exposed mouse initiated with MCA is shown in Figure 3. Tumors (arrows) appeared white in color and semi-translucent to opaque upon initial gross exam (A). After fixation, tumors were more defined which facilitated enumeration (B). At 30 weeks, all tumors were $\geq 1 \mathrm{~mm}$ and $\leq 4 \mathrm{~mm}$ in diameter; however, the majority were $\sim 1 \mathrm{~mm}$. Welding PM (*) was found in all exposed mouse lungs and appeared dark brown to black in color.

\section{Histopathological evaluation of lung lesions, inflammation, and welding PM presence}

Figure 4 shows the histopathological assessment (including preneoplastic epithelial proliferations) for multiplicity (left panel) and the total numbers of lung lesions (right panel) from all groups. Histopathology confirmed the gross results and showed a remarkable similarity between the ratios for gross tumor counts and those enumerated microscopically (see Figure 2). Tumor incidence was not different among the corn oil- or MCA-treated groups and was, as expected, lower than that obtained by gross exam, $21.9 \pm 3.4 \%$ and $85.0 \pm 4.1 \%$, respectively. Inflammation and welding PM severity scores and number of each lung lesion type are shown in Table 2. Welding PM was found in all exposed lungs and detected in slightly greater amounts in the high dose groups. Lymphoid cell infiltrates, an indicator of inflammation, consisted of peribronchial/ perivascular associated lymphocytes, macrophages, and 


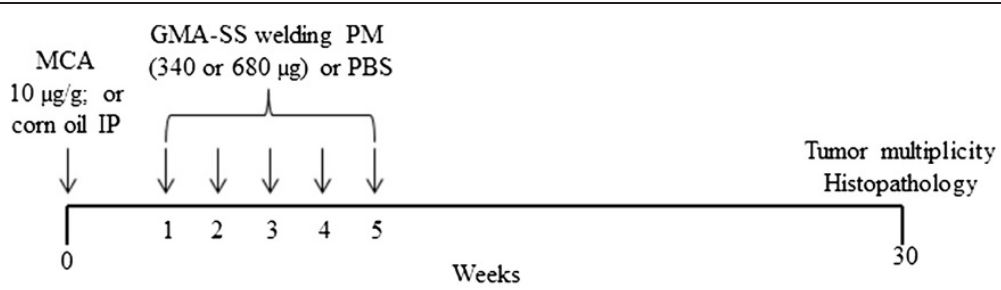

\begin{tabular}{|c|c|c|c|c|c|c|}
\hline & \multicolumn{2}{|c|}{ Sham } & \multicolumn{2}{c|}{ GMA-SS Low } & \multicolumn{2}{c|}{ GMA-SS High } \\
\hline Block & $\begin{array}{c}\text { Corn oil } \\
(\mathrm{n}=)\end{array}$ & $\begin{array}{c}\text { MCA } \\
(\mathrm{n}=)\end{array}$ & $\begin{array}{c}\text { Corn oil } \\
(\mathrm{n}=)\end{array}$ & $\begin{array}{c}\text { MCA } \\
(\mathrm{n}=)\end{array}$ & $\begin{array}{c}\text { Corn oil } \\
(\mathrm{n}=)\end{array}$ & $\begin{array}{c}\text { MCA } \\
(\mathrm{n}=)\end{array}$ \\
\hline 1 & 7 & 8 & 7 & 8 & 7 & 8 \\
\hline 2 & 8 & 7 & 7 & 7 & 8 & 7 \\
\hline 3 & 7 & 8 & 6 & 7 & 7 & 8 \\
\hline 4 & 8 & 7 & 8 & 6 & 8 & 7 \\
\hline ngroup & 30 & 30 & 28 & 28 & 30 & 30 \\
\hline
\end{tabular}

Figure 1 Experimental protocol and block design for the two-stage carcinogenesis model to assess GMA-SS welding PM as a tumor promoter in A/J mice. Mice were IP injected with MCA (initiator) or corn oil (vehicle) then 1 week later exposed to GMA-SS (340 or $680 \mu \mathrm{g}$ ) or PBS (vehicle; sham) by pharyngeal aspiration once a week for 5 weeks. The study was carried out in four blocks (1 block/day for 4 days/week) for randomization. All treatment combinations were represented in each block. Body weights were recorded at week 0 , then at each weekly aspiration exposure and at every two weeks thereafter. Mice were sacrificed 30 weeks post-initiation and tumor multiplicity was evaluated.

plasma cells and were increased in all welding PM-exposed groups (Figure 5, left panel). Of note, there was no significant difference in inflammatory cell infiltrates in the shamexposed mice treated with MCA or corn oil 30 weeks after IP injection. This dose of MCA has also been shown to be non-inflammatory by bronchoalveolar lavage analysis in the A/J mouse [12]. Microscopically, adenomas and preneoplastic epithelial proliferations were in the majority, which is consistent with the model and previous observations $[11,13]$. There were a greater number of malignant lesions in the MCA/GMA-SS high group compared to MCA/sham; 7 out of 29 mice were found to have a CA or $\mathrm{C}$ (Figure 5, right panel). In the MCA/ GMA-SS low group, there were 2 animals with advanced lesions, one with a multiple $C A$, so the significance in this case should likely be dismissed.

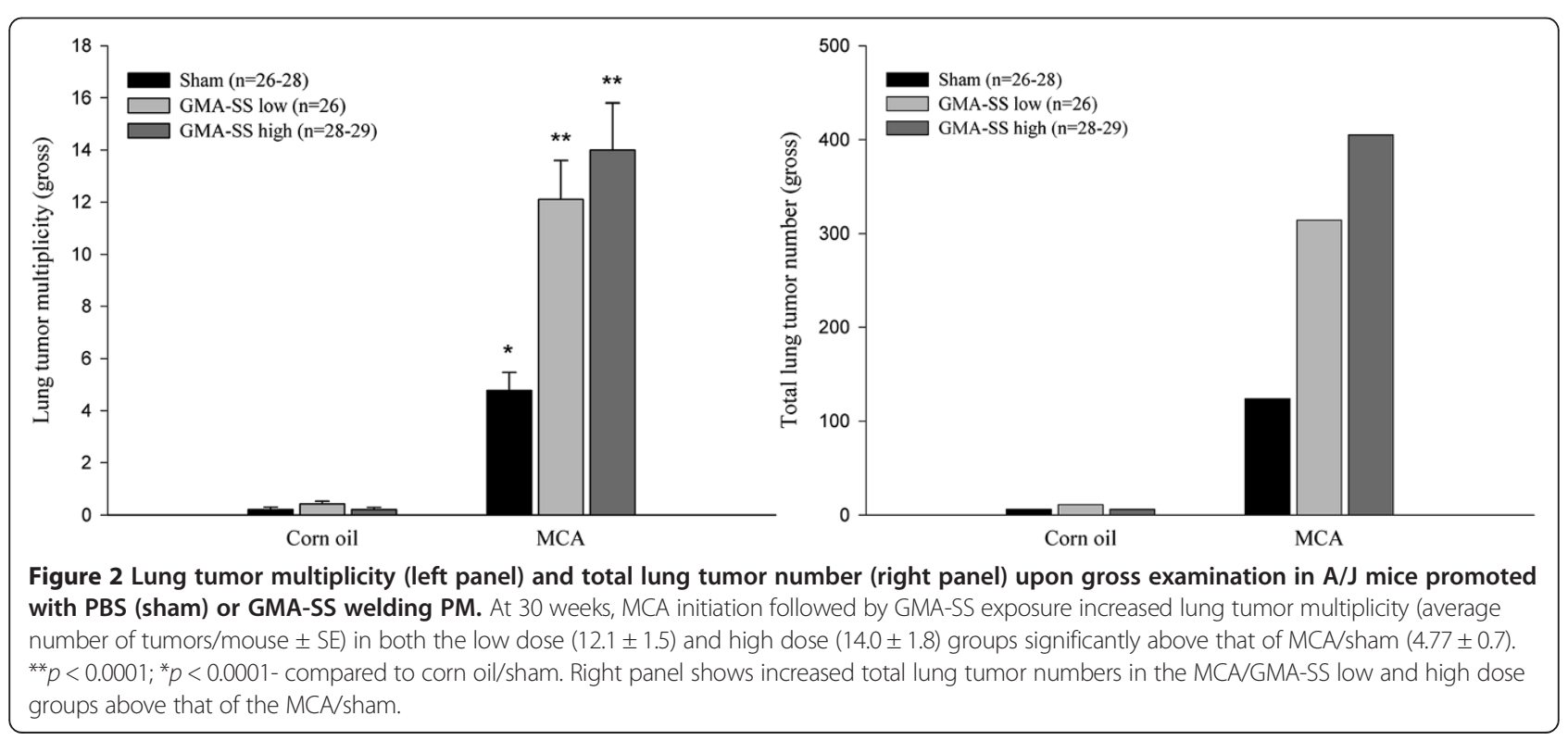


Table 1 Total tumor number across individual lung lobes in A/J mice following exposure to GMA-SS welding PM at 30 weeks post-initiation with MCA or corn oil

\begin{tabular}{|c|c|c|c|c|c|c|}
\hline & $\mathrm{n}$ & Left & Apical & Cardiac & Diaphragmatic & Azygos \\
\hline Corn oil/Sham & 28 & 1 & 1 & 2 & 2 & 0 \\
\hline Corn oil/GMA-SS low & 26 & 4 & 3 & 2 & 1 & 1 \\
\hline Corn oil/GMA-SS high & 28 & 4 & 1 & 0 & 1 & 0 \\
\hline MCA/Sham & 26 & $52^{*}$ & $12^{*}$ & $13^{*}$ & $39^{*}$ & $8^{*}$ \\
\hline MCA/GMA-SS low & 26 & $119^{* *}$ & $46^{* *}$ & $40^{\#}$ & $81^{\#}$ & $28^{\#}$ \\
\hline MCA/GMA-SS high & 29 & $132^{* *}$ & $64^{* *}$ & $66^{* *}$ & $106^{* *}$ & $37^{\#}$ \\
\hline
\end{tabular}

GMA-SS gas metal arc-stainless steel, $P M$ particulate matter, MCA 3-methylcholanthrene.

${ }^{*} p<0.002$ - compared to corn oil/sham.

${ }^{* *} p<0.0007,{ }^{*} p<0.004$ - compared to MCA/sham.

\section{Discussion}

The novel finding of this study was a highly significant increase in lung tumor multiplicity in mice promoted with SS welding PM, which was consistent and significant across all five individual lung regions. This response was observed 30 weeks after MCA-initiation. Also of note, there were more malignant lesion types in the MCA/high dose welding PM group which suggests that not only is the rate of tumor formation being increased by welding PM, but the progression to malignancy appears to be affected with higher doses of particulate. This study is the first to link enhanced lung tumor formation and welding fume exposure in vivo and provide animal evidence to support epidemiological findings.

A $25 \%$ to $40 \%$ increased risk of lung cancer has been associated with the welding occupation [14-16]. Indeed, the proportionate mortality ratio for welders for lung cancer is 1.2 [17]. Even though some evidence exists to the contrary, epidemiological studies generally support an increased risk, but they are limited in number; animal studies are scarce [3]. Because welders work under widely diverse conditions and co-exposures such as silica, smoking, and asbestos may be involved, cumulative exposure data and a complete occupational history may not always be available $[15,18,19]$. Therefore, controlled animal studies to elucidate the underlying factors of welding fume-related lung carcinogenesis are long overdue.

Previously, we assessed the ability of different types of welding PM to act as a complete lung carcinogen in lung tumor susceptible A/J mice. Efforts of those studies were ultimately negative but hinted at a potential weak carcinogenic effect of SS welding PM, as a borderline significant $(p=0.057)$ increase in grossly observed lung tumor incidence (i.e., presence or absence of tumors) was found $[10,11,20,21]$. In addition, histopathology at 78 weeks after exposure revealed presence of SS welding PM which was associated with a mild, but significant, chronic inflammatory cell influx in the lung tissue. Of note, these effects were not observed following exposure to mild steel (MS) welding PM composed largely of iron oxide [11]. Also, to complement those studies, the lung toxicity and gene expression profiles in the tumor susceptible A/J and resistant C57BL/6J (B6) mouse were compared following pharyngeal aspiration of GMA welding PM [11,22]. Interestingly, a significantly greater magnitude of overt lung toxicity (polymorphonuclear leukocyte influx, lung cytotoxicity and permeability) and an attenuated resolution of the inflammatory response to different types of welding PM were found in the A/J versus the B6 mouse strain. Results from the microarray analysis
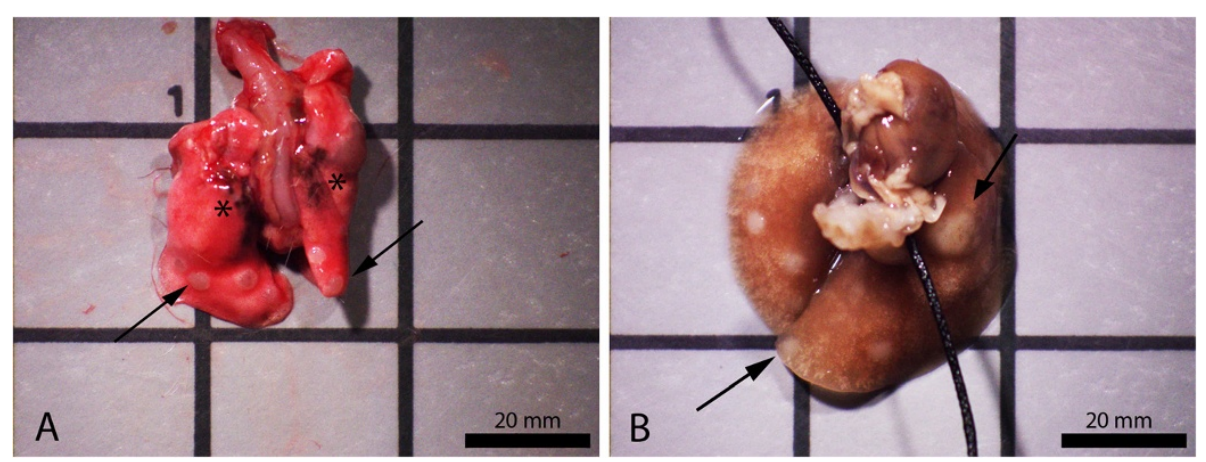

Figure 3 Gross images of lung tumors promoted by GMA-SS welding PM 30 weeks after initiation with MCA. Panel A represents the lung tumor morphology before fixation panel $\mathbf{B}$ is $24 \mathrm{~h}$ after fixation. Asterisks $(*)$-indicate areas of welding PM deposition. The arrows ( $\uparrow$ )-indicate lung tumors. The majority of tumors were $\sim 1 \mathrm{~mm}$ in diameter. 

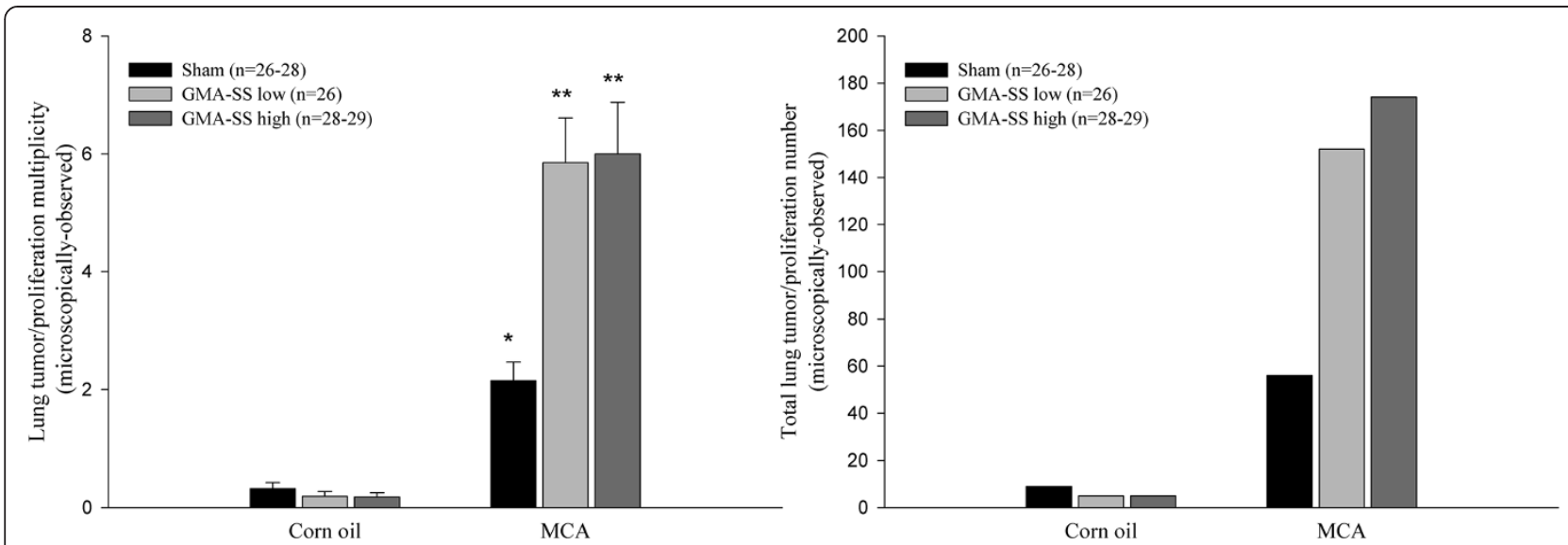

Figure 4 Lung tumor/proliferation multiplicity (left panel) and total number (right panel) microscopically observed in $\mathrm{A} / \mathrm{J}$ mice promoted with PBS (sham) or GMA-SS welding PM. At 30 weeks, MCA initiation followed by GMA-SS exposure increased multiplicity (average number of tumors and proliferations/mouse $\pm \mathrm{SE})$ in both the low dose $(5.85 \pm 0.76)$ and high dose $(6.00 \pm 0.87)$ groups significantly above that of MCA/sham (2.15 \pm 0.32$)$. ${ }^{*} p<0.0001 ;{ }^{*} p<0.0001$ - compared to corn oil/sham. Right panel shows increased total lung lesion numbers in the MCA/GMA-SS low and high dose groups above that of the MCA/sham.

confirmed those aforementioned responses and revealed a greater lung transcriptional gene activation as well as a prolonged dysregulation of immunomodulatory genes after welding PM exposure in the A/J versus the B6 mouse [22]. In all cases, the lung toxicity and transcriptional effects were greater with the carcinogenic metal-containing SS welding fume when directly compared to a MS welding fume. Therefore, historical data in our laboratory suggested that fumes containing $\mathrm{Cr}$ and $\mathrm{Ni}$ were the most toxic, persisted in the lung longer as compared to other types, and were possibly tumorigenic in vivo.

The A/J mouse lung tumor bioassay is well-characterized, has good inter- and intra-laboratory reproducibility, and has been widely used for testing hundreds of potential lung carcinogens, such as tobacco smoke and polycyclic hydrocarbons [23-25]. It also continues to be useful for evaluation of chemointerventive agents of lung neoplasia $[24,26,27]$. This strain is susceptible to both chemically- induced and spontaneous lung adenomas compared to the resistant B6 mouse [23]. Morphological, molecular, and histological features of the lung tumors that arise in these mice resemble human adenocarcinomas; therefore, findings in this model have direct human relevance [28]. Indeed, tumor susceptibility in the A/J strain has been associated with a polymorphism in intron 2 of Kras and this finding is pertinent to human lung adenocarcinoma development because $\sim 35 \%$ of these human tumor types contain Kras oncogenes $[29,30]$.

In humans, chronic lung inflammatory conditions such as asthma and chronic obstructive pulmonary disease are associated with increased risk of lung cancer and epidemiology suggests $\sim 25 \%$ of human cancers are attributed to chronic inflammation [31-33]. Microenvironments of chronic lung inflammation, largely dominated by macrophages and other leukocytes, create a milieu rich in reactive oxygen species and cytokines that

Table 2 Severity scores for abnormal morphological findings and number of microscopically observed lung lesion types in A/J mice following exposure to GMA-SS welding fume PM at $\mathbf{3 0}$ weeks post-initiation with MCA or corn oil

\begin{tabular}{|c|c|c|c|c|c|c|c|}
\hline & $\begin{array}{l}\text { Lymphoid } \\
\text { infiltrates }\end{array}$ & $\begin{array}{l}\text { Welding-fume } \\
\text { laden cells }\end{array}$ & Preneoplasia & $\begin{array}{l}\text { Adenoma within } \\
\text { preneoplasia }\end{array}$ & Adenoma & Adenocarcinoma & Carcinoma \\
\hline Corn oil/Sham & $0.25 \pm 0.07$ & $0.00 \pm 0.00$ & 5 & 2 & 2 & 0 & 0 \\
\hline Corn oil/GMA-SS low & $1.79 \pm 0.07^{* *}$ & $2.12 \pm 0.04$ & 1 & 0 & 3 & 1 & 0 \\
\hline Corn oil/GMA-SS high & $1.84 \pm 0.06^{* *}$ & $2.29 \pm 0.07^{\#}$ & 0 & 1 & 4 & 0 & 0 \\
\hline MCA/Sham & $0.15 \pm 0.00$ & $0.00 \pm 0.00$ & 16 & 5 & 34 & 0 & 1 \\
\hline MCA/GMA-SS low & $1.44 \pm 0.08^{* *}$ & $1.90 \pm 0.05$ & $61^{* *}$ & $17^{* *}$ & $70^{* *}$ & $4^{* *}$ & 0 \\
\hline MCA/GMA-SS high & $1.57 \pm 0.06^{* *}$ & $2.12 \pm 0.06^{\#}$ & $65^{* *}$ & 9 & $93^{* *}$ & $6^{* *}$ & 1 \\
\hline
\end{tabular}

GMA-SS Gas metal arc-stainless steel, PM Particulate matter, MCA 3-methylcholanthrene.

${ }^{*}$ Severity scores were average of the right and left lung lobe score and are presented as mean \pm standard error, lymphoid infiltrates are peribronchial/perivascular associated lymphocytes, macrophages, and plasma cells. Severity was scored as: $1=$ minimal, $2=$ mild, $3=$ moderate, $4=$ marked, $5=$ severe.

${ }^{* *} p<0.01$ - compared to the corresponding sham in the corn oil- or MCA-treated groups.

${ }^{\#} p<0.001$ - compared to the corresponding GMA-SS low in the corn oil- or MCA-treated groups. 


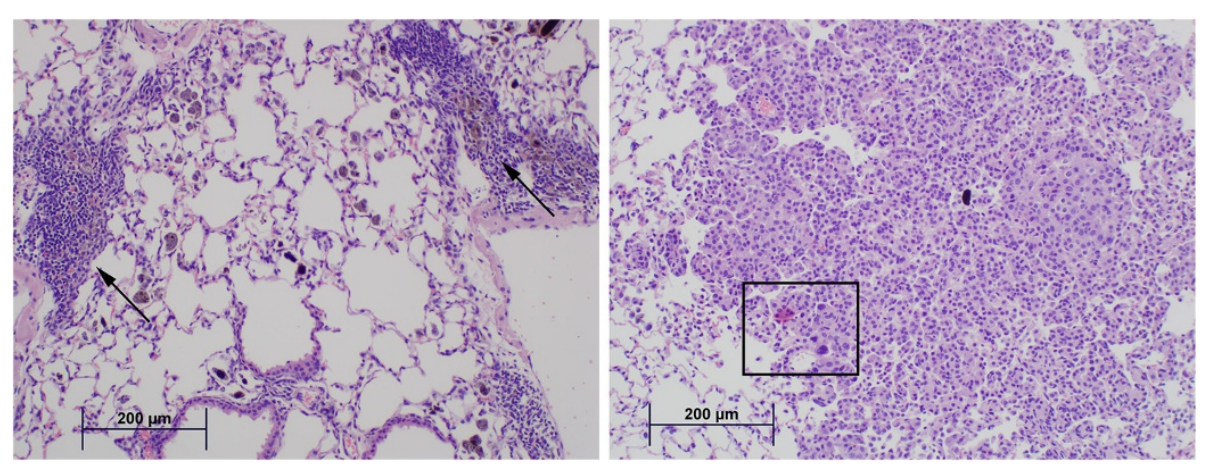

Figure 5 Photomicrographs of lung tissue from MCA-treated mice. Representative photomicrographs were captured at 30 weeks after MCA-initiation and show presence of lymphoid infiltrates (i.e., inflammatory cell infiltrates consisting of peribronchial/perivascular associated lymphocytes, macrophages, and plasma cells) and welding PM (arrows) in the MCA/low GMA-SS group (left panel). An area of malignant transformation (rectangle) - larger cells with irregular nuclei and associations-in the MCA/high GMA-SS group (right panel).

may promote tumorigenesis [34-36]. Indeed, in the mouse model, quantitative trait loci (QTL) that control genetic susceptibility to lung inflammation colocalize with tumor susceptibility QTL [37]. Two-stage carcinogenesis in lung tissue was first reported by Witschi et al. when repeated IP injections of butylated hydroxytoluene (BHT), a synthetic food additive and antioxidant, increased lung adenoma multiplicity in both Swiss-Webster and A/J mice initiated with a single dose of the potent carcinogen urethane 9-15 weeks prior [38]. The model of BHT tumor promotion continues to provide mechanistic insight into the critical role that inflammation has in lung tumor initiation and promotion $[35,39,40]$. More recently, this two-stage model was used to demonstrate the in vivo promoter activity of vanadium pentoxide $\left(\mathrm{V}_{2} \mathrm{O}_{5}\right)$, a component of environmental and occupational $\mathrm{PM}$, in $\mathrm{A} / \mathrm{J}, \mathrm{BALB} / \mathrm{cJ}$, and C57BL/6 J mice initiated with MCA 20 weeks prior [12]. In agreement with our earlier findings that strain-dependent $(\mathrm{A} / \mathrm{J}>\mathrm{B} 6)$ lung responses were evident after welding $\mathrm{PM}$ exposure, Rondini et al. found that $\mathrm{V}_{2} \mathrm{O}_{5}$-mediated lung inflammation and subsequent tumor multiplicity also showed strain dependency $(\mathrm{A} / \mathrm{J}>\mathrm{BALB} / \mathrm{cJ}>\mathrm{B} 6)[11,12,22]$. In this study, the observed inflammatory cell infiltration and highly significant increased tumor multiplicity after MCA/GMASS welding PM exposure, combined with our previous evidence of chronic inflammation due to SS particle persistence in the lung, further supports the role of inflammation in the promotion of lung tumors in $\mathrm{A} / \mathrm{J}$ mice.

GMA-SS welding PM is poorly soluble and contains toxic metals, namely $\mathrm{Cr}(\mathrm{VI})$, which is carcinogenic, especially in the particulate form [3]. In vitro, this fume has also been shown to cause greater DNA damage, lipid peroxidation, and radical generation compared to MS fume [41]. Increased DNA damage has also been reported in blood leukocytes from welders exposed to $\mathrm{Cr}$ and $\mathrm{Ni}$ fumes [42,43]. Once inhaled, $\mathrm{Cr}(\mathrm{VI})$ particles are retained primarily by the lung and tend to accumulate near major bifurcations, where they may persist for as long as twenty years [44,45]. A possible mechanism for $\mathrm{Cr}(\mathrm{VI})$ carcinogenicity involves the slow release over time of chromate ions from particulate compounds adhered to the cell surface. These ions may escape extracellular reduction by ascorbate, which then allows for uptake by lung epithelial cells causing tumor formation [46]. Indeed, a concentration-dependent induction of aneuploidy has been shown in normal human bronchial fibroblast and immortalized human bronchial epithelial cells exposed to particulate chromate [47,48]. In addition, $\mathrm{Cr}(\mathrm{VI})$ may act synergistically with $\mathrm{Ni}$, present in lower amounts in this fume, as suggested by comutagenicity studies [49]. In rats and mice, GMA-SS fume exhibited a slower lung clearance timeline compared to a more soluble manual metal arc-SS (MMA-SS) and GMAMS fume [11,50]. Thus, slower lung clearance, together with the greater lung toxicity profile of this fume in vivo, may significantly contribute to its increased tumor promoter activity.

No threshold limit value-time weighted average (TLVTWA) exists for welding fume. The previous TLV-TWA of $5 \mathrm{mg} / \mathrm{m}^{3}$ for welding fume was retracted in 2004 by the American Conference of Governmental Industrial Hygienists [51]. In this study, we used welding PM exposures equivalent to 1.84 and 3.67 years of work exposures at $5 \mathrm{mg} / \mathrm{m}^{3}$ and $\mathrm{Cr}(\mathrm{VI})$ exposures of 5.4 and 10.8 years at $5 \mu \mathrm{g} / \mathrm{m}^{3}$ in a human for the low and high doses, respectively. Previously published reports have indicated that airborne concentrations of $\mathrm{Cr}(\mathrm{VI})$ in industries using SS welding can be $50-400 \mu \mathrm{g} / \mathrm{m}^{3}$ [52]. Welders oftentimes work in confined spaces which can increase the total fume exposure to $>20 \mathrm{mg} / \mathrm{m}^{3}$ [53]. Because freshly generated welding fume induces greater lung inflammation than "aged" fume, such as that used in this study, and one-third of the dose by inhalation results in about 2 to 3 times the pulmonary toxicity, the exposures used herein are reasonable $[11,21,54]$. However, the bolus delivery of the particles 
is an obvious limitation in this study, even though the doses were repeated over a five- week time frame (1 exposure/week). As such, welding fume by inhalation is 6 to 9 times more potent than by pharyngeal aspiration [55]. The mechanisms of increased toxicity by inhalation are likely related to the free radical generation of freshly generated welding fume compared to "aged" fumes that are collected onto filters then used in instillation studies $[41,54]$. Given the role of inflammation in tumor promotion described above, the combined interpretation of our previous studies strongly suggests that a significantly lower mass deposition by inhalation would have similar results as those in this study.

\section{Conclusions}

The current research supports epidemiological findings that SS welding fume may have carcinogenic potential. At 30 weeks after MCA-initiation, an average of 7.33 to 9.23 tumors/mouse were grossly enumerated after exposure to GMA-SS welding PM. Indeed, the effect was highly significant $(\mathrm{p}<0.0001)$. GMA-SS welding PM did not increase multiplicity or incidence by 30 weeks in the corn oiltreated A/J mouse. Therefore, in this experimental model, this fume does not appear to be a potent initiator and shorten the timeframe for induction of lung tumors, which agrees with previous results $[11,21]$. Taken together, the intrinsic toxicity of GMA-SS welding PM, the chronic lung inflammatory milieu, and the leaching of $\mathrm{Cr}(\mathrm{VI})$ from the particles may allow for potential tumor promotion in a susceptible population.

\section{Methods}

\section{Animals}

Male A/J mice, age 5-6 weeks, were purchased from Jackson Laboratories (Bar Harbor, ME) and housed in an AAALAC-accredited, specific pathogen-free, environmentally controlled facility. All mice were free of endogenous viral pathogens, parasites, mycoplasmas, Helicobacter, and CAR Bacillus. Mice were individually housed in ventilated cages and provided HEPA-filtered air under a controlled light cycle (12 h light/12 h dark). Animals were acclimated to the animal facility for a minimum of 1 week and allowed access to a conventional diet (6\% Irradiated NIH31 Diet, Harlan Teklad, Madison, WI) and tap water ad libitum. All procedures were performed using protocols approved by the National Institute for Occupational Safety and Health Institutional (NIOSH) Animal Care and Use Committee.

\section{Generation of GMA-SS welding PM and analysis of $\mathrm{Cr}(\mathrm{VI})$ levels}

Welding fumes were generated for this study by the $\mathrm{NIOSH}$ robotic welding system which includes a 6-axis robotic arm, power supply, water-cooled arc welding torch, and a wire feeder; as previously detailed [7]. SS welding wire was Lincoln Electric E308 LSi; the shield gas was $\mathrm{Ar} / \mathrm{CO}_{2} 95 \% / 5 \%$ at 19 liters/min. The welding material in the baseplates was $1 / 4$ inch A-36 carbon steel. Welding was done in axial spray mode at 26.5 volts, 240 amperes, 325 inches/min wire feed, and 15 inches/min travel.

Fumes from the weld area were sampled onto electrostatic medium filters (PE 13060NA, Hollingsworth and Vose, East Walpole, MA), and PM was recovered by gentle suction, then ground by shaking for $30 \mathrm{sec}$ in a Wig-L-Bug grinder using a metal-free disposable polyethylene vial with two $1 / 8$ inch silicon nitride-coated ceramic balls. The ground material was anti-static treated, and $5 \mathrm{mg}$ samples were weighed into $15 \mathrm{ml}$ polycarbonate centrifuge tubes.

Three replicate welding PM samples were analyzed for $\mathrm{Cr}(\mathrm{VI})$ levels using NIOSH method 7605 [56]. Briefly, $5 \mathrm{ml}$ of extraction solution $\left(3 \% \mathrm{Na}_{2} \mathrm{CO}_{3} / 2 \% \mathrm{NaOH}\right)$ were added to each $5 \mathrm{mg}$ sample, and the tubes were sonicated in a bath for $30 \mathrm{~min}$. This procedure extracts both soluble and insoluble $\mathrm{Cr}(\mathrm{VI})$ present in the fumes. Analysis used a Dionex HPIC-AS7 column with $250 \mathrm{mM}\left(\mathrm{NH}_{4}\right)_{2} \mathrm{SO}_{4} /$ $100 \mathrm{mM} \mathrm{NH}_{4} \mathrm{OH}$ mobile phase and a postcolumn reagent (2.0 mM diphenylcarbazide/10\% methanol/1 $\mathrm{N} \mathrm{H}_{2} \mathrm{SO}_{4}$ ) with absorbance detection at $540 \mathrm{~nm}$. Four concentrations of standards were made from a certified $\mathrm{Cr}(\mathrm{VI})$ solution, covering a range of $0.4-4 \mu \mathrm{g} / \mathrm{ml}$. The estimated limit of detection is $0.02 \mu \mathrm{g}$, and the method range is 0.05 to $20 \mu \mathrm{g}$ of $\mathrm{Cr}(\mathrm{VI})$. Total metal analysis was done as previously described using inductively coupled plasma-atomic emission spectroscopy (ICP-AES) using NIOSH method 7300 modified for microwave digestion [7,57]. The metal solubility of this fume is low ( 0.006 soluble:insoluble) and the mass median aerodynamic diameter of the sample is $0.255 \mu \mathrm{m}$, as previously determined [58].

\section{Experimental protocols for animal exposures and sacrifice} A/J mice, 176 in total, were organized into 6 groups using a block design for randomization (Figure 1). During week 1 , mice were intraperitoneally (IP) injected with an initiator, 3-methylcholanthrene (MCA), (Sigma, St. Louis, MO) dissolved in corn oil (Sigma, St. Louis, MO) at a dose of $10 \mu \mathrm{g} / \mathrm{g}$ body weight or corn oil alone. One week postinitiation, mice were exposed to GMA-SS welding PM suspended in phosphate-buffered saline (PBS) without calcium and magnesium by pharyngeal aspiration as previously described [59]. Briefly, each mouse was placed in a bell jar with gauze moistened with isoflurane (Abbott Laboratories, Abbott Park, IL) until slowed breathing was observed. The mouse was then suspended by its top incisors, on a slanted board in a supine position. The tongue was extended with forceps and the test suspension was placed by pipette at the back of the throat. The tongue was held until the solution was aspirated into the lung and 
3 deep breaths were observed. The mouse recovered fully in its cage within $15 \mathrm{sec}$. Mice were exposed once a week for 5 weeks to either 340 or $680 \mu \mathrm{g}$ of freshly prepared GMA-SS welding PM or PBS (sham control). Welding PM was briefly sonicated ( $<1 \mathrm{~min})$ after suspension in PBS, then vortexed immediately before each individual animal exposure.

The cumulative exposures over the 5 week time course were $1.7 \mathrm{mg}$ and $3.4 \mathrm{mg}$, respectively, and these were chosen based on previous published results $[10,11,20]$. Previous research has estimated that a welder exposed to $5 \mathrm{mg} / \mathrm{m}^{3}$ for an $8 \mathrm{~h}$ day would be expected to have a lung burden of 7.7. $\mathrm{mg}$ alveolar deposition [60]. Utilizing $102 \mathrm{~m}^{2}$ for human and $0.05 \mathrm{~m}^{2}$ murine alveolar surface area [61], $7.7 \mathrm{mg}$ is converted to a murine equivalence of $3.77 \mu \mathrm{g}$. Assuming 100\% alveolar deposition of the aspirate, the low dose of GMA-SS PM used in this study would be equivalent to 450 days, or 1.84 working years, of a worker being exposed at $5 \mathrm{mg} / \mathrm{m}^{3}$ for $8 \mathrm{~h} / \mathrm{d}$. The high dose would be equivalent to 900 days, or 3.68 working years. The current PEL for $\mathrm{Cr}(\mathrm{VI})$ is $5 \mu \mathrm{g} / \mathrm{m}^{3}$ which was readjusted in 2006 from $52 \mu \mathrm{g} / \mathrm{m}^{3}$ [62]. Therefore, a human exposed to $5 \mu \mathrm{g} / \mathrm{m}^{3} \mathrm{Cr}(\mathrm{VI})$ for $8 \mathrm{~h}$ would result in $7.7 \mu \mathrm{g}$ alveolar deposition with a murine daily equivalence of $3.77 \mathrm{ng}$. In this study, $\mathrm{Cr}(\mathrm{VI})$ in the welding $\mathrm{PM}$ was measured to be $2920 \mu \mathrm{g} / \mathrm{g}$, or $0.29 \%$. Thus, the low and high doses contained $4.96 \mu \mathrm{g}$ and $9.93 \mu \mathrm{g}$ of $\mathrm{Cr}(\mathrm{VI})$, respectively. An exposure level of $5 \mu \mathrm{g} / \mathrm{m} 3 \mathrm{Cr}(\mathrm{VI})$ for $8 \mathrm{~h} / \mathrm{d}$, would be equivalent to 5.4 years for the low and 10.8 years for the high dose.

One block/day (4 days/week) was completed for each stage of the 6-week protocol. MCA was chosen as the initiating agent based on the efficient response of the $\mathrm{A} / \mathrm{J}$ mouse to this carcinogen compared to other mouse strains [63]. The dose of MCA and basic protocol in A/J mice were derived from a study by Rondini et al. [12].

At 30 weeks post-initiation, mice were sacrificed over a 4 day period (1 block/day). Mice were anesthetized with an IP overdose of Sleepaway (26\% sodium pentobarbital, 7.8\% isopropyl alcohol and 20.7\% propylene glycol, Fort Dodge Animal Health, Fort Dodge, IA) then weighed. Once unresponsive, the abdomen and thoracic cavity were opened and examined for any abnormalities and the vena cava was cut to exsanguinate the mouse. The whole lung was excised then inflated and fixed with 10\% neutral buffered formalin for $24 \mathrm{~h}$. Lungs were then examined and tumors were enumerated and measured in a blinded fashion by two individuals with the aid of a Leica MZ6 stereomicroscope (Leica Microsystems, Inc., Buffalo Grove, IL). Apparent merged tumors, defined as a single tumor pattern in double-nodule form or an apparent collision of two different tumors, were counted as one. Gross images were taken using an Olympus DP21 digital camera (Olympus America, San Jose, CA).
Whole lungs were embedded in paraffin then a $5 \mu \mathrm{m}$ standardized section was cut. Slides were stained with hematoxylin and eosin and interpreted by a contracted board certified veterinary pathologist in a blinded fashion for morphological changes and proliferative/neoplastic lesions. All lung lobes were evaluated from every animal in each group. If abnormal changes were found, severity was scored as follows: $1=$ minimal, $2=$ mild, $3=$ moderate, $4=$ marked, $5=$ severe. The final severity score reflects the average of the right and left lung lobe scores (see Table 2). Proliferative/neoplastic changes were counted and identified as $\mathrm{P}=$ preneoplastic epithelial proliferation, $\mathrm{AP}=\mathrm{ad}-$ enoma arising within a proliferation, $\mathrm{A}=$ adenoma, $\mathrm{CA}=$ carcinoma arising within an adenoma, $\mathrm{C}=$ carcinoma, or $\mathrm{MC}=$ microcarcinoma [64]. Since examination of a single histological section per lung underestimates the total number of lesions per lung, the gross count at necropsy would be more representative of the response. However, for completeness, both microscopic and gross exam total lung tumor numbers were statistically evaluated in this study.

\section{Statistics}

All analyses were performed using SAS/STAT version 9.3 (SAS Institute Inc., Cary, NC) for Windows. Binary outcomes of tumor incidence (presence or absence) for each region and for the total were analyzed using Fishers Exact test. Tumor counts were analyzed using negative binomial regression for each region and the total because the Poisson regression on counts was overdispersed. All analyses were stratified by promoter. Only animals surviving the entire 30 week time course were used for analysis.

\section{Abbreviations}

B6: C57BL/6 J; Cr(VI): Hexavalent chromium; Fe: Iron; GMA-SS: Gas metal arcStainless steel; GMA-MS: Gas metal arc-mild steel; IARC: International agency for research on cancer; IP: Intraperitoneal; LOD: Limit of detection; Mn: Manganese; MMA-SS: Manual metal arc-stainless steel; MCA: 3-methylcholanthrene; Ni: Nickel; NIOSH: National institute for occupational safety and health; PM: Particulate matter; PEL: Permissible exposure limit; PBS: Phosphate buffered saline; SE: Standard error; TLV-TWA: Threshold limit value-time weighted average.

\section{Competing interest}

The authors declare that they have no competing interest.

\section{Authors' contributions}

PCZE and JMA conceived and designed the study. PCZE drafted the manuscript. PCZE, TGM, AE and LAB performed the animal exposures, animal sacrifices, counted the lung tumors, and assisted with lung preparation for histopathology. MK generated the welding fume sample for the exposure and MLK statistically analyzed all data. All authors read and approved the final manuscript.

\section{Acknowledgement}

We appreciate Patsy Willard and Diana Richardson for the histologic preparation of the slides. We also thank Dr. Linda Sargent and David Lowry for the protocol to prepare the MCA.

\section{Disclaimer}

The findings and conclusions in this report are those of the authors and do not necessarily represent the views of the National Institute for Occupational Safety and Health. 
Received: 19 April 2013 Accepted: 3 September 2013

Published: 5 September 2013

\section{References}

1. IARC: Report of the advisory group to recommend priorities for IARC Monographs during 2010-2014. Lyon: Internal report 08/001; 2008.

2. t Mannetje A, Brennan P, Zaridze D, Szeszenia-Dabrowska N, Rudnai P Lissowska J, Fabianova E, Cassidy A, Mates D, Bencko V, et al: Welding and lung cancer in central and Eastern Europe and the United Kingdom. Am J Epidemiol 2012, 175:706-714.

3. IARC: Chromium, nickel and welding. IARC Monogr Eval Carcinog Risks Hum 1990, 49:1-648.

4. Sjogren B, Hansen KS, Kjuus H, Persson PG: Exposure to stainless steel welding fumes and lung cancer: a meta-analysis. Occup Environ Med 1994, 51:335-336.

5. Antonini JM: Health effects of welding. Crit Rev Toxicol 2003, 33:61-103.

6. Sferlazza SJ, Beckett WS: The respiratory health of welders. Am Rev Respir Dis 1991, 143:1134-1148.

7. Antonini JM, Afshari AA, Stone S, Chen B, Schwegler-Berry D, Fletcher WG, Goldsmith WT, Vandestouwe KH, McKinney W, Castranova V, Frazer DG: Design, construction, and characterization of a novel robotic welding fume generator and inhalation exposure system for laboratory animals. J Occup Environ Hyg 2006, 3:194-203.

8. Zeidler-Erdely PC, Erdely A, Antonini JM: Immunotoxicology of arc welding fume: worker and experimental animal studies. J Immunotoxicol 2012, 9:411-425.

9. Keane M, Stone S, Chen B, Slaven J, Schwegler-Berry D, Antonini J: Hexavalent chromium content in stainless steel welding fumes is dependent on the welding process and shield gas type. J Environ Monit 2009, 11:418-424

10. Solano-Lopez C, Zeidler-Erdely PC, Hubbs AF, Reynolds SH, Roberts JR, Taylor MD, Young SH, Castranova V, Antonini JM: Welding fume exposure and associated inflammatory and hyperplastic changes in the lungs of tumor susceptible A/J mice. Toxicol Pathol 2006, 34:364-372

11. Zeidler-Erdely PC, Kashon ML, Battelli LA, Young SH, Erdely A, Roberts JR, Reynolds SH, Antonini JM: Pulmonary inflammation and tumor induction in lung tumor susceptible $\mathrm{A} / \mathrm{J}$ and resistant $\mathrm{C} 57 \mathrm{BL} / 6 \mathrm{~J}$ mice exposed to welding fume. Part Fibre Toxicol 2008, 5:12.

12. Rondini EA, Walters DM, Bauer AK: Vanadium pentoxide induces pulmonary inflammation and tumor promotion in a strain-dependent manner. Part Fibre Toxicol 2010, 7:9.

13. Gunning WT, Castonguay A, Goldblatt PJ, Stoner GD: Strain A/J mouse lung adenoma growth patterns vary when induced by different carcinogens. Toxicol Pathol 1991, 19:168-175.

14. Ambroise D, Wild P, Moulin JJ: Update of a meta-analysis on lung cance and welding. Scand J Work Environ Health 2006, 32:22-31.

15. Moulin JJ: A meta-analysis of epidemiologic studies of lung cancer in welders. Scand J Work Environ Health 1997, 23:104-113.

16. Simonato L, Fletcher AC, Andersen A, Anderson K, Becker N, Chang-Claude J, Ferro G, Gerin M, Gray CN, Hansen KS, et al: A historical prospective study of European stainless steel, mild steel, and shipyard welders. $\mathrm{Br} J$ Ind Med 1991, 48:145-154.

17. National center for health statistics. http://www2a.cdc.gov/drds/ WorldReportData/FigureTableDetails.asp? FigureTableID=982\&GroupRefNumber=T13-02

18. Steenland K: Ten-year update on mortality among mild-steel welders. Scand J Work Environ Health 2002, 28:163-167.

19. Danielsen $T E$, Langard $S$, Andersen $A$ : Incidence of lung cancer among shipyard welders investigated for siderosis. Int J Occup Environ Health 1998, 4:85-88

20. Zeidler-Erdely PC, Battelli LA, Salmen-Muniz R, Li Z, Erdely A, Kashon ML, Simeonova PP, Antonini JM: Lung tumor production and tissue metal distribution after exposure to manual metal arc-stainless steel welding fume in A/J and C57BL/6J mice. J Toxicol Environ Health A 2011, 74:728-736.

21. Zeidler-Erdely PC, Battelli LA, Stone S, Chen BT, Frazer DG, Young SH, Erdely A, Kashon ML, Andrews R, Antonini JM: Short-term inhalation of stainless steel welding fume causes sustained lung toxicity but no tumorigenesis in lung tumor susceptible A/J mice. Inhal Toxicol 2011, 23:112-120.

22. Zeidler-Erdely PC, Kashon ML, Li S, Antonini JM: Response of the mouse lung transcriptome to welding fume: effects of stainless and mild steel fumes on lung gene expression in $\mathrm{A} / \mathrm{J}$ and $\mathrm{C} 57 \mathrm{BL} / 6 \mathrm{~J}$ mice. Respir Res 2010, 11:70.

23. Shimkin MB, Stoner GD: Lung tumors in mice: application to carcinogenesis bioassay. Adv Cancer Res 1975, 21:1-58.

24. Stinn W, Berges A, Meurrens K, Buettner A, Gebel S, Lichtner RB, Janssens K Veljkovic E, Xiang Y, Roemer E, Haussmann HJ: Towards the validation of a lung tumorigenesis model with mainstream cigarette smoke inhalation using the A/J mouse. Toxicology 2013, 305:49-64.

25. Witschi $\mathrm{H}$ : The complexities of an apparently simple lung tumor model: the A/J mouse. Exp Toxicol Pathol 2005, 57(Suppl 1):171-181.

26. Castonguay A, Pepin P, Stoner GD: Lung tumorigenicity of NNK given orally to A/J mice: its application to chemopreventive efficacy studies. Exp Lung Res 1991, 17:485-499.

27. Nesnow S, Mass MJ, Ross JA, Galati AJ, Lambert GR, Gennings C, Carter WH $\mathrm{Jr}$, Stoner GD: Lung tumorigenic interactions in strain $\mathrm{A} / \mathrm{J}$ mice of five environmental polycyclic aromatic hydrocarbons. Environ Health Perspect 1998, 106(Suppl 6):1337-1346.

28. Malkinson AM: Primary lung tumors in mice: an experimentally manipulable model of human adenocarcinoma. Cancer Res 1992, 52:2670s-2676s.

29. Malkinson AM, You M: The intronic structure of cancer-related genes regulates susceptibility to cancer. Mol Carcinog 1994, 10:61-65.

30. You M, Wang Y, Stoner G, You L, Maronpot R, Reynolds SH, Anderson M: Parental bias of Ki-ras oncogenes detected in lung tumors from mouse hybrids. Proc Natl Acad Sci U S A 1992, 89:5804-5808

31. Punturieri A, Szabo E, Croxton TL, Shapiro SD, Dubinett SM: Lung cancer and chronic obstructive pulmonary disease: needs and opportunities for integrated research. J Natl Cancer Inst 2009, 101:554-559.

32. Santillan AA, Camargo CA Jr, Colditz GA: A meta-analysis of asthma and risk of lung cancer (United States). Canc Causes Contr 2003, 14:327-334

33. Colotta F, Allavena P, Sica A, Garlanda C, Mantovani A: Cancer-related inflammation, the seventh hallmark of cancer: links to genetic instability. Carcinogenesis 2009, 30:1073-1081.

34. Lu H, Ouyang W, Huang C: Inflammation, a key event in cancer development. Mol Cancer Res 2006, 4:221-233.

35. Vikis HG, Gelman AE, Franklin A, Stein L, Rymaszewski A, Zhu J, Liu P, Tichelaar JW, Krupnick AS, You M: Neutrophils are required for 3-methylcholanthrene-initiated, butylated hydroxytoluene-promoted lung carcinogenesis. Mol Carcinog 2012, 51:993-1002.

36. Zaynagetdinov R, Sherrill TP, Polosukhin W, Han W, Ausborn JA, McLoed AG, McMahon FB, Gleaves LA, Degryse AL, Stathopoulos GT, et al: A critical role for macrophages in promotion of urethane-induced lung carcinogenesis. J Immunol 2011, 187:5703-5711.

37. Malkinson AM, Radcliffe RA, Bauer AK: Quantitative trait locus mapping of susceptibilities to butylated hydroxytoluene-induced lung tumor promotion and pulmonary inflammation in CXB mice. Carcinogenesis 2002, 23:411-417.

38. Witschi H, Williamson D, Lock S: Enhancement of urethan tumorigenesis in mouse lung by butylated hydroxytoluene. J Natl Cancer Inst 1977, 58:301-305.

39. Bauer AK, Dwyer-Nield LD, Hankin JA, Murphy RC, Malkinson AM: The lung tumor promoter, butylated hydroxytoluene (BHT), causes chronic inflammation in promotion-sensitive BALB/CByJ mice but not in promotion-resistant CXB4 mice. Toxicology 2001, 169:1-15.

40. Bauer AK, Dwyer-Nield LD, Keil K, Koski K, Malkinson AM: Butylated hydroxytoluene (BHT) induction of pulmonary inflammation: a role in tumor promotion. Exp Lung Res 2001, 27:197-216.

41. Leonard SS, Chen BT, Stone SG, Schwegler-Berry D, Kenyon AJ, Frazer D, Antonini JM: Comparison of stainless and mild steel welding fumes in generation of reactive oxygen species. Part Fibre Toxicol 2010, 7:32

42. Danadevi K, Rozati R, Banu BS, Grover P: Genotoxic evaluation of welders occupationally exposed to chromium and nickel using the Comet and micronucleus assays. Mutagenesis 2004, 19:35-41.

43. Costa M, Zhitkovich A, Toniolo P: DNA-protein cross-links in welders: molecular implications. Cancer Res 1993, 53:460-463.

44. Ishikawa Y, Nakagawa K, Satoh Y, Kitagawa T, Sugano H, Hirano T, Tsuchiya E: Characteristics of chromate workers' cancers, chromium lung deposition and precancerous bronchial lesions: an autopsy study. Br J Cancer 1994, 70:160-166.

45. Ishikawa Y, Nakagawa K, Satoh Y, Kitagawa T, Sugano H, Hirano T, Tsuchiya E: "Hot spots" of chromium accumulation at bifurcations of chromate workers' bronchi. Cancer Res 1994, 54:2342-2346. 
46. Nickens KP, Patierno SR, Ceryak S: Chromium genotoxicity: a double-edged sword. Chem Biol Interact 2010, 188:276-288.

47. Holmes AL, Wise SS, Sandwick SJ, Lingle WL, Negron VC, Thompson WD, Wise JP Sr: Chronic exposure to lead chromate causes centrosome abnormalities and aneuploidy in human lung cells. Cancer Res 2006, 66:4041-4048.

48. Xie H, Holmes AL, Wise SS, Huang S, Peng C, Wise JP Sr: Neoplastic transformation of human bronchial cells by lead chromate particles. Am J Respir Cell Mol Biol 2007, 37:544-552.

49. Salnikow K, Zhitkovich A: Genetic and epigenetic mechanisms in metal carcinogenesis and cocarcinogenesis: nickel, arsenic and chromium. Chem Res Toxicol 2008, 21:28-44.

50. Antonini JM, Roberts JR, Stone S, Chen BT, Schwegler-Berry D, Chapman R, Zeidler-Erdely PC, Andrews RN, Frazer DG: Persistence of deposited metals in the lungs after stainless steel and mild steel welding fume inhalation in rats. Arch Toxicol 2011, 85:487-498.

51. ACGIH: Threshold limit values for chemical substances and physical agents and biological exposure indices. http://www.acgih.org/resources/press/ TLV2004list.htm.

52. NTP: Report on carcinogens. 12th edition. http://ntp.niehs.nih.gov/go/roc12.

53. Korczynski RE: Occupational health concerns in the welding industry. Appl Occup Environ Hyg 2000, 15:936-945.

54. Antonini JM, Clarke RW, Krishna Murthy GG, Sreekanthan P, Jenkins N, Eagar TW, Brain JD: Freshly generated stainless steel welding fume induces greater lung inflammation in rats as compared to aged fume. Toxicol Lett 1998, 98:77-86.

55. Erdely A, Salmen-Muniz R, Liston A, Hulderman T, Zeidler-Erdely PC, Antonini JM, Simeonova PP: Relationship between pulmonary and systemic markers of exposure to multiple types of welding particulate matter. Toxicology 2011, 287:153-159.

56. NIOSH: Method 7605, hexavalent chromium by ion chromatography. NIOSH manual of analytical methods. http://www.cdc.gov/niosh/docs/2003-154/.

57. NIOSH: Elements by ICP: method 7300. NIOSH manual of analytical methods. http://www.cdc.gov/niosh/docs/2003-154/.

58. Antonini JM, Stone S, Roberts JR, Chen B, Schwegler-Berry D, Afshari AA, Frazer DG: Effect of short-term stainless steel welding fume inhalation exposure on lung inflammation, injury, and defense responses in rats. Toxicol Appl Pharmacol 2007, 223:234-245.

59. Rao GV, Tinkle S, Weissman DN, Antonini JM, Kashon ML, Salmen R, Battelli LA, Willard PA, Hoover MD, Hubbs AF: Efficacy of a technique for exposing the mouse lung to particles aspirated from the pharynx. J Toxicol Environ Health A 2003, 66:1441-1452.

60. Erdely A, Hulderman T, Salmen-Muniz R, Liston A, Zeidler-Erdely PC, Chen BT, Stone S, Frazer DG, Antonini JM, Simeonova PP: Inhalation exposure of gas-metal arc stainless steel welding fume increased atherosclerotic lesions in apolipoprotein E knockout mice. Toxicol Lett 2011, 204:12-16.

61. Stone KC, Mercer RR, Gehr P, Stockstill B, Crapo JD: Allometric relationships of cell numbers and size in the mammalian lung. Am J Respir Cell Mol Biol 1992, 6:235-243.

62. OSHA: Occupational exposure to hexavalent chromium. Final rule. Fed Regist 2006, 71:10099-10385.

63. Eastman A, Bresnick E: Persistent binding of 3-methylcholanthrene to mouse lung DNA and its correlation with susceptibility to pulmonary neoplasia. Cancer Res 1979, 39:2400-2405

64. Belinsky SA, Devereux TR, Foley JF, Maronpot RR, Anderson MW: Role of the alveolar type II cell in the development and progression of pulmonary tumors induced by 4-(methylnitrosamino)-1-(3-pyridyl)-1-butanone in the A/J mouse. Cancer Res 1992, 52:3164-3173.

doi:10.1186/1743-8977-10-45

Cite this article as: Zeidler-Erdely et al:: Lung tumor promotion by chromium-containing welding particulate matter in a mouse model. Particle and Fibre Toxicology 2013 10:45.

\section{Submit your next manuscript to BioMed Central and take full advantage of:}

- Convenient online submission

- Thorough peer review

- No space constraints or color figure charges

- Immediate publication on acceptance

- Inclusion in PubMed, CAS, Scopus and Google Scholar

- Research which is freely available for redistribution
C Biomed Central 